\title{
PENGEMBANGAN MOBILE LEARNING PADA MATA KULIAH GEOMETRI DENGAN PENDEKATAN MATEMATIK REALISTIK DITINJAU DARI KEMAMPUAN BERPIKIR KRITIS MAHASISWA
}

\author{
Achmad Buchori' $^{1)}$, Rasiman²), Dina Prasetyowati' ${ }^{3)}$, Kartinah $^{4)}$ \\ Universitas PGRI Semarang \\ Email ${ }^{1}$ : buccherypgri@gmail.com \\ Email'2): mpdrasiman@yahoo.co.id \\ Email3): dinaprasetyowati@gmail.com \\ Email4): tinamath.507@gmail.com
}

\begin{abstract}
ABSTRAK
Tujuan penelitian ini adalah mengembangkan mobile learning dengan pendekatan matematik realistik pada mata kuliah Geometri ditinjau dari kemampuan berpikir kritis. Adapun target khusus yang ingin dicapai dalam penelitian ini yaitu menguji efektifitas perangkat pembelajaran mobile learning dengan pendekatan matematik realistik pada mata kuliah Geometri ditinjau dari kemampuan berpikir kritis mahasiswa Program Studi pendidikan Matematika Universitas PGRI Semarang. Prosedur pengembangan perangkat pembelajaran menggunakan model yang dikembangkan Borg dan Gall yang meliputi 10 tahapan. Dalam penelitian ini tahapan yang dilakukan hanya sampai pada tahap kelima yaitu Main Product Revision. Analisis pada penelitian ini dilakukan dengan membandingkan antara data dengan kriteria-kriteria, yaitu praktis dan efektif. Pada kriteria praktis menunjukkan hasil evaluasi ahli media sebesar 93\%, ahli materi sebesar 83\%, dan mahasiswa sebesar 86\%. Dalam kriteria efektif produk ditunjukan dari prestasi belajar kelas eksperimen lebih baik dibanding dengan kelas kontrol. Dari analisis menggunakan uji-t didapatkan $\mathrm{t}_{\text {hitung }}>\mathrm{t}_{\text {tabel }}$ yaitu 5,98>1,71, maka Ho ditolak artinya pembelajaran dengan menggunakan media mobile learning dengan pendekatan matematik realistik lebih baik dibandingkan dengan pembelajaran konvensional. Jadi dapat disimpulkan bahwa media mobile learning dengan pendekatan realistik matematik ini efektif digunakan sebagai proses pembelajaran.
\end{abstract}

Kata Kunci: Mobile Learning, Geometri, Pendekatan Realistik Matematik.

\begin{abstract}
The purpose of this research is to develop a mobile learning media with realistic mathematical approach to the Geometry course in terms of critical thinking skills. The specific targets to be achieved in this research is to test the effectiveness of the learning media Mobile learning with realistic mathematical approach to the Geometry course in terms of critical thinking skills of students in Mathematics Education Department University of PGRI Semarang. The procedures of the learning software development is by using the model developed Borg and Gall which includes 10 stages. In this research, the phase is done only to the fifth stage, namely Main Product Revision. The analysis in this study is conducted by comparing the data with the criteria, that is practical and effective. On practical criteria shows the results of the evaluation by the expert of media by $93 \%$, expert of material by $83 \%$, and students by $86 \%$. Effective products in the criteria indicated from experimental class learning achievement better than the control class. From the analysis using t-test obtained: $t$ count $>t$ table ie 5.98 $>1.71$, then Ho is rejected. It means the learning by using mobile learning media with realistic mathematical approach is better than the conventional learning. It can be concluded that mobile learning media with realistic mathematical approach is effectively used as a learning process.
\end{abstract}

Keywords: Mobile Learning, Geometry, Mathematical Realistic Approach. 


\section{PENDAHULUAN}

Di era globalisasi sekarang ini, ada banyak teknologi yang dapat digunakan sebagai media pembelajaran dalam proses pembelajaran matematika. Para pelaku pendidikan banyak memanfaatkan perkembangan teknologi untuk digunakan sebagai media pembelajaran. Teknologi internet adalah salah satu teknologi yang memungkinkan setiap orang dapat melakukan pembelajaran secara mobile atau dapat disebut mobile learning (m-learning). Kombinasi antara telekomunikasi dengan teknologi internet dapat memungkinkan pengembangan sistem m-learning sebagai media pembelajaran. Hal ini sesuai dengan penelitian Martinez (2014) tentang Development of a Mobile Service on a Wifi Network for the Evaluation of Mathematical Skills yang menunjukkan bahwa dengan pengembangan sistem evaluasi online melalui handphone membuat proses penilaian menjadi mudah dan lebih efektif. Saat ini teknologi $\mathrm{m}$ learning memang masih dalam proses pengembangan, akan tetapi, teknologi $m$ learning sebagai media pembelajaran merupakan salah satu teknologi yang prospektif di masa depan.

Di sisi lain, teknologi m-learning memiliki beberapa keterbatasan antara lain: besarnya daya yang terbatas, kapasitas memori tidak sebesar komputer, kecepatan pemrosesan tidak secepat komputer, monitor lebih kecil dari pada komputer. Oleh karena itu, aplikasi m-learning harus dirancang dengan lebih efektif, efisien, dan optimal untuk mengatasi keterbatasannya. Aplikasi m-learning dapat dikembangkan dengan menggunakan Java. Java merupakan open standard yang portable telah memberikan dukungan bagi pengembangan aplikasi yang beragam salah satunya adalah Java 2 Platform Micro
Edition (J2ME). J2ME adalah aplikasi dari java yang digunakan pada perangkat bergerak, salah satunya adalah handphone.

Handphone merupakan salah satu gadget yang paling banyak digunakan oleh masyarakat. Penggunaan handphone sebagai telekomunikasi dewasa ini masih belum dimanfaatkan dengan optimal oleh pendidikan. Penggunaan handphone sebagai media pembelajaran tentu menarik dan praktis, karena dapat diakses di mana saja dan kapan saja. Hal ini sesuai penelitian Shao (2014) tentang Mo Math: An Innovative Design of a Mobile based System for Supporting Primary School Mathematics in Tanzania, yang menunjukkan bahwa lebih dari 50\% guru dan siswa di primary school di Tanzania menyukai Mo Math karena mudah diakses dan digunakan dimana saja.

Menurut Soedjadi (2004), matematika realistik dikembangkan berdasarkan pandangan Freudenthal yang berpendapat bahwa matematika merupakan kegiatan manusia yang lebih menekankan aktivitas siswa untuk mencari, menemukan, dan membangun sendiri pengetahuan yang diperlukan sehingga pembelajaran menjadi terpusat pada siswa. Hans Freudenthal berpendapat bahwa matematika merupakan aktivitas insani (human activities) dan harus dikaitkan dengan realitas. Sehingga perlu mengaitkan materi matematika ke "dunia riil” artinya segala sesuatu yang dapat kita jumpai, yang berhubungan dengan kehidupan sehari-hari serta lingkungan sekitar kemudian dikaitkan dan dapat memperjelas konsep matematika. Hal ini diperjelas tentang kegunaan mobile learning dan matematika realistik diatas, sangat sesuai dengan penelitian Heck (2003) tentang How a Realistic Mathematics Education Approach and Microcomputer-Based Laboratory 
Worked in Lessons on Graphing at an Indonesian Junior High School, yang menunjukkan bahwa hasil belajar siswa SMP di Surabaya menjadi lebih baik dengan penerapan pembelajaran RME berbasis ICT.

Di program studi pendidikan matematika, penguasaan materi mata kuliah geometri sangat mutlak bagi mereka calon pendidik, hal ini karena mereka nantinya harus mampu mengajar di sekolah setelah mereka lulus. Dalam mengajar di sekolah harus mampu menguasai materi baik secara keilmuan maupun aplikasi media pembelajaran sehingga menarik bagi siswa. Berdasarkan wawancara dengan beberapa pengampu mata kuliah geometri diperoleh bahwa pembelajaran mata kuliah Geometri yang berlangsung selama ini di Program Studi Pendidikan Matematika Universitas PGRI Semarang belum mengoptimalkan kemajuan di bidang Informatika Teknologi (IT) dan belum pernah menggunakan mobile learning sebagai strategi mengajar dosen.

Berdasarkan uraian tersebut, maka dapat dirumuskan permasalahan sebagai berikut. (1) Bagaimanakah mengembangkan mobile learning pada mata kuliah geometri dengan pendekatan matematika realistik ditinjau dari kemapuan berpikir kritis mampu menarik minat dan motivasi belajar mahasiswa? (2) Apakah pembelajaran dengan menggunakan mobile learning dengan pendekatan matematika realistik ditinjau dari kemampuan berpikir kritis dapat berlangsung secara efektif?. Tujuan penelitian yang ingin dicapai dalam penelitian dan pengembangan ini adalah menghasilkan mobile learning pada mata kuliah geometri dengan pendekatan matematika realistik ditinjau dari kemampuan berpikir kritis mahasiswa sehingga mampu meningkatkan minat dan motivasi belajar mahasiswa.
Mobile learning (m-learning) merupakan paradigma pembelajaran memanfaatkan teknologi dan perangkat mobile yang perkirakan akan mengalami perkembangan pesat dan potensial seiring dengan perkembangan teknologi mobile itu sendiri. Hal ini dapat dilihat dari data statistik bahwa dari 240 juta jumlah penduduk Indonesia 45-50 juta di antaranya adalah pengguna atau konsumen seluler. (http://p4tkmatematika.org). Sedangkan secara teknis, perangkat mobile yang beredar saat ini sebenarnya telah memiliki kapabilitas untuk menjalankan konten-konten berupa multimedia maupun aplikasi software. Selain itu konten yang ada kebanyakan masih bersifat hiburan dan belum banyak dimanfaatkan untuk pembelajaran. Dalam pengembangan mobile learning ini digunakan aplikasi software Java dan WAP serta memanfaatkan teknologi GPRS/ CDMA dan teknologi transfer lain seperti bluetooth, infrared, untuk transfer dan instalasi aplikasi. Perangkat yang dapat digunakan untuk pembelajaran ini adalah telepon seluler yang mendukung WAP dan Java.

Menurur Ally (2009: 1) bahwa, "m-learning menggunakan teknologi wireless mobile untuk mengakses informasi dan belajar dimana saja dan kapan saja. Hal tersebut dapat diartikan bahwa pembelajar dapat mengontrol sendiri apa yang akan dipelajari dan dari mana tempat dia akan belajar". Dari definisi ini dapat disimpulkan bahwa mobile learning adalah pertemuan dari mobile computing dan e-learning yang dihasilkan dari ilmu pengetahuan dan kemampuan di bidang mobile-technology yang dapat digunakan untuk belajar dan mengajar tanpa ada batas tempat dan waktu.

Soedjadi (2004) menyatakan bahwa pembelajaran matematika dengan pendekatan realistik pada dasarnya adalah 
pemanfaatan realita atau lingkungan yang dipahami peserta didik untuk memperlancar proses pembelajaran matematika sehingga dapat mencapai tujuan pendidikan matematika secara lebih baik dari pada masa yang lalu. Lebih lanjut dijelaskan yang dimaksud realita adalah hal-hal yang nyata atau konkret yang dapat diamati atau dipahami peserta didik lewat membayangkan, sedangkan yang dimaksud dengan lingkungan adalah lingkungan tempat peserta didik berada, baik lingkungan sekolah, keluarga maupun masyarakat yang dapat dipahami peserta didik.

Selanjutnya mahasiswa diberi kesempatan untuk mengaplikasikan konsep-konsep matematika untuk memecahkan masalah sehari-hari atau masalah dalam bidang lainnya. Oleh karena itu PMR berbeda dengan pembelajaran matematika yang menggunakan pendekatan lainnya yang selama ini digunakan sebagian besar guru matematika di sekolah, karena dengan pendekatan yang digunakan selama ini cenderung pada pemberian informasi dan matematika digunakan sebagai alat bantu.

Prinsip utama dalam PMR ada tiga hal. Menurut Gravemeijer (2001) ketiga prinsip kunci PMR tersebut adalah Guided Reinvention/Progressive Mathematizing (menemukan kembali dengan bimbingan/ matematisasi progressif), Didactical Phenomenologi (fenomena didaktik) dan Self-developed Models (model yang dibangun sendiri oleh siswa). Dengan menerapkan tiga prinsip utama PMR tersebut, maka pembelajaran matematika di sekolah dilaksanakan dengan menempatkan realitas dan pengalaman mahasiswa sebagai titik awal pembelajaran. Masalah realita dalam kehidupan nyata dijadikan sebagai sumber munculnya konsep-konsep matematika.
Berpikir kritis dan berpikir kreatif perwujudan dari berpikir tingkat tinggi (higher order thinking). Hal tersebut karena kemampuan berpikir tersebut merupakan kompetensi kognitif tertinggi yang perlu dikuasai peserta didik di kelas. Berpikir kritis dapat dipandang sebagai kemampuan berpikir peserta didik untuk membandingkan dua atau lebih informasi, misalkan informasi yang diterima dari luar dengan informasi yang dimiliki. Bila terdapat perbedaan atau persamaan, maka ia akan mengajukan pertanyaan atau komentar dengan tujuan untuk mendapatkan penjelasan.

Berpikir kritis adalah sebuah proses dimana seseorang mencoba untuk menjawab secara rasional pertanyaanpertanyaan yang tidak dapat dijawab secara mudah dan dimana semua informasi yang relevan tidak tersedia (Inch et al., 2006: 5). Berpikir kritis sebagai sebuah pengkajian yang tujuannya adalah untuk mengkaji situasi, fenomena, pertanyaan, atau masalah untuk mendapatkan sebuah hipotesis atau kesimpulan yang mengintegrasikan semua informasi yang tersedia dan oleh karena itu dapat secara meyakinkan dijustifikasi.

Berdasarkan beberapa pengertian berpikir kritis di atas, maka dapat disimpulkan bahwa seseorang berpikir kritis dengan ciri-ciri: (1) menyelesaikan suatu masalah dengan tujuan tertentu, (2) menganalisis, menggeneralisasikan, mengorganisasikan ide berdasarkan fakta/ informasi yang ada, dan (3) menarik kesimpulan dalam menyelesaikan masalah tersebut secara sistematik dengan argumen yang benar.

\section{METODE PENELITIAN}

Penelitian ini termasuk jenis R\&D (research and development) penelitian 
pengembangan. Prosedur pengembangan menggunakan model yang dikembangkan Borg dan Gall. Borg \& Gall (1983) menyatakan bahwa prosedur penelitian pengembangan pada dasamya terdiri dari dua tujuan utama, yaitu: (1) mengembangkan produk, dan (2) menguji keefektifan produk dalam mencapai tujuan. Pengembangan yang dihasilkan berupa produk dengan tahapantahapan dari Brog dan Gall. Produk diharapkan dapat meningkatkan kualitas pembelajaran sehingga menghasilkan sumber daya yang mumpuni dan relevan terhadap kebutuhan. Dalam penelitian ini produk yang dihasilkan adalah mobile learning dengan pendekatan matematika realisitik pada matakuliah Geometri ditinjau dari kemampuan berpikir kritis mahasiswa Universitas PGRI Semarang.

Populasi dalam penelitian ini adalah seluruh mahasiswa semester 2 Prodi Pendidikan Matematika Universitas PGRI Semarang tahun ajaran 2015/2016. Pengambilan sampel data penelitian ini menggunakan teknik purposive sampling dan diambil dua kelas Prodi Pendidikan Matematika Universitas PGRI Semarang tahun ajaran 2015/2016. Data yang dikumpulkan pada pengembangan mobile learning berupa data kuantitatif sebagai data pokok dan data kualitatif berupa saran dan masukan dari responden sebagai data tambahan. Data tersebut memberi gambaran mengenai kelayakan produk yang dikembangkan.

Setelah produk melalui validasi oleh beberapa ahli, peneliti menganalisis hasil yang didapatkan dari uji ahli. Hal ini perlu dilakukan untuk merumuskan produk seperti apa yang dimaksud oleh para pakar. Peneliti akan mendapatkan inti sari dari beberapa penilaian oleh para pakar sehingga revisi apa saja yang akan dilakukan menjadi jelas. Di dalam tahapan revisi produk, produk yang sudah melalui uji ahli akan direvisi agar lebih efektif dan sesuai yang diharapkan berdasarkan penilaian secara rasional yang dilakukan oleh para pakar.

Uji coba produk adalah kegiatan untuk memberi penilaian terhadap produk dalam hal pemakaian. Penilaian pada tahap uji coba produk ini dimaksudkan untuk mengetahui fakta lapangan yang ada dan keberhasilan dari media pembelajaran yang dibuat. Untuk uji coba produk, digunakan metode One-Group Pretest-Posttest Design yang merupakan bagian dari metode Pre-Eksperimental Design. Dalam pendidikan tinggi secara formal, hasil belajar mahasiswa baik kognitif maupun psikomotorik menjadi parameter keberhasilan suatu proses pembelajaran.

\section{HASIL DAN PEMBAHASAN \\ Proses Pengembangan Mobile Learning Pada Mata Kuliah Geometri}

Produk media pembelajaran berupa desain mobile learning dengan Pendekatan Matematika Relalistik pada materi Geometri dalam pembelajaran matematika sebagai hasil dari pengembangan ini divalidasi dan diuji dengan angket. Validasi terdiri dari validasi media, validasi materi dan hasil tanggapan mahasiswa terhadap produk yang dihasilkan.

Validasi oleh ahli media dan ahli materi ini dilakukan supaya media yang akan diujicobakan benar-benar layak untuk digunakan dalam penelitian. Produk pengembangan yang dievaluasi oleh ahli media yaitu mobile learning dengan menggunakan angket yang harus diisi oleh ahli media. Angket terdiri dari penilaian aspek umum, aspek penyajian pembelajaran, aspek kelayakan bahasa, aspek kelayakan kegrafikan. Produk pengembangan yang dievaluasi oleh ahli materi yaitu mobile learning dengan menggunakan angket yang 
harus diisi oleh ahli materi. Angket terdiri dari penilaian aspek umum, aspek substansi materi, aspek desain pembelajaran.
Hasil penilaian ahli media dan ahli materi dipaparkan pada diagram batang berikut.

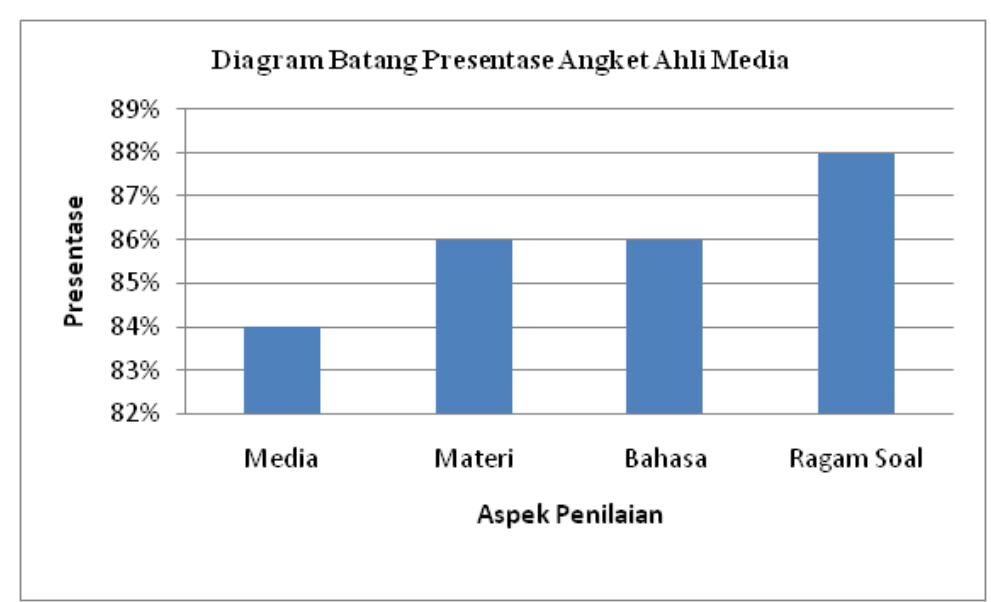

Gambar 1. Diagram Batang Presentase Hasil Validasi Ahli Media

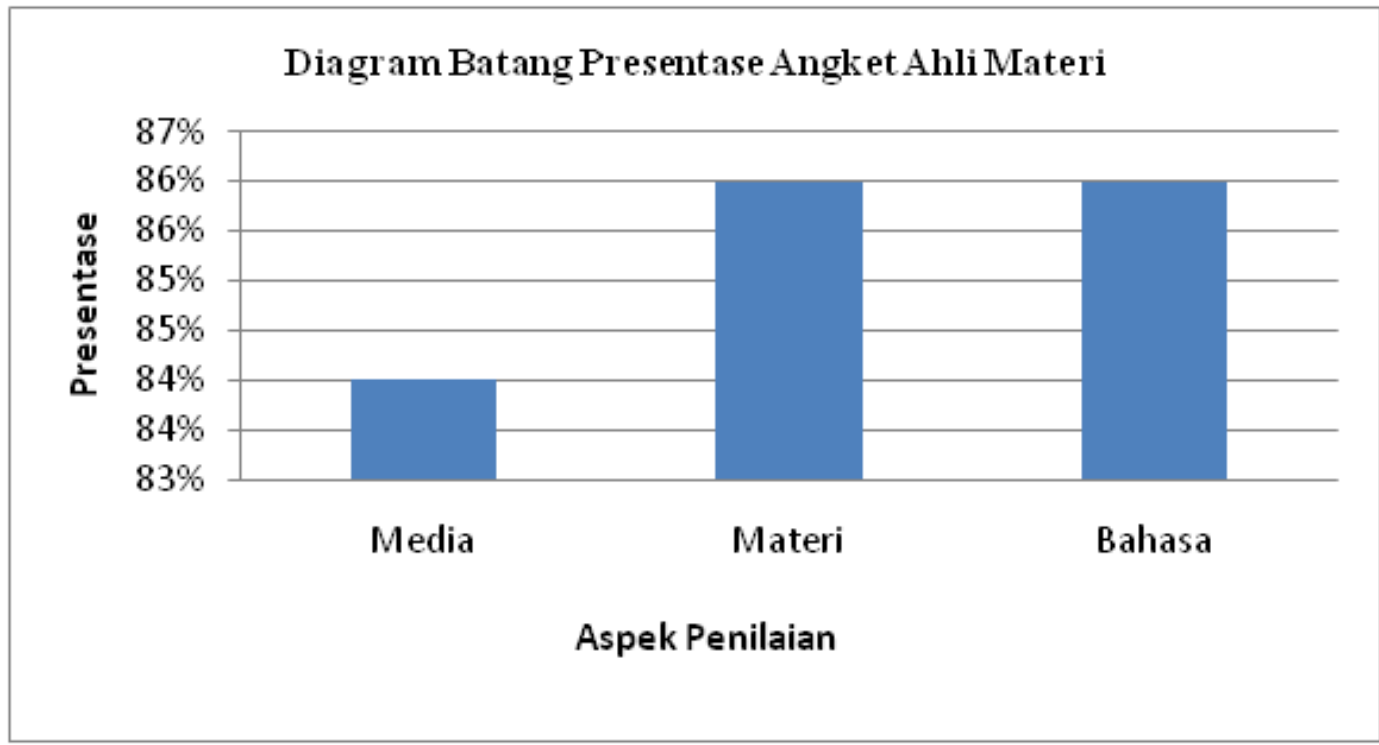

Gambar 2. Diagram Batang Presentase Hasil Validasi Ahli Materi

Dari perhitungan didapatkan persentase kelayakan mobile learning sebesar 93\% oleh ahli media. Setelah dikonversikan dengan tabel konversi skala, media mobile learning berada pada rentang $81 \%$ - $100 \%$. Sehingga menempatkan posisi pada kriteria sangat baik, sedangkan untuk ahli materi didapatkan persentase kelayakan mobile learning sebesar $83 \%$ oleh ahli materi. Setelah dikonversikan dengan tabel konversi skala, media mobile learning berada pada rentang $81 \%$ - 100\%. Sehingga menempatkan posisi pada kriteria sangat baik.

Ujicoba dilakukan setelah hasil evaluasi yang dilakukan oleh ahli media dan ahli materi, selanjutnya peneliti melakukan revisi berdasarkan saran para ahli maka produk diuji cobakan ke kelas eksperimen. Media mobile learning ini ditanggapi oleh 15 mahasiswa yang berasal 
dari kelas 2A. Mahasiswa menanggapi media mobile learning ini dengan cara mengisi angket yang diberikan peneliti untuk diisi mahasiswa. Angket diberikan kepada mahasiswa setelah mahasiswa selesai menggunakan mobile learning. Hal ini dilakukan agar peneliti mengetahui seberapa baiknya mobile learning ini digunakan untuk mahasiswa. Angket terdiri dari penilaian aspek media, aspek materi, aspek bahasa, aspek ragam soal, aspek desain media. Hasil penilaian oleh mahasiswa dipaparkan pada diagram lingkaran berikut.

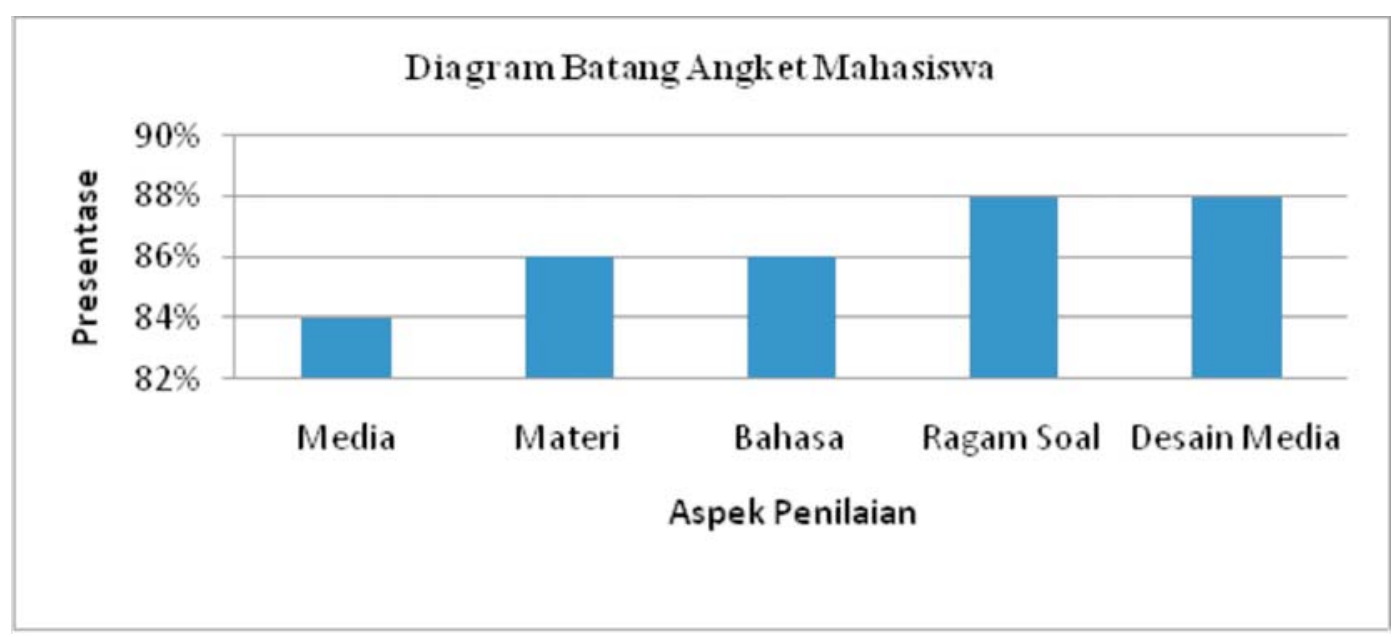

Gambar 3. Diagram Lingkaran Presentase Hasil Evaluasi Mahasiswa

persentase kelayakan mobile learning sebesar $86 \%$ oleh mahasiswa. Setelah dikonversikan dengan tabel konversi skala, media mobile learning berada pada rentang $81 \%$ - 100\%. Sehingga menempatkan posisi pada kriteria sangat baik.

\section{Hasil Uji Coba Lapangan}

Pelaksanaan uji coba dilaksana-kan oleh mahasiswa kelas 2A sebagai kelas eksperimen dan 2B sebagai kelas kontrol di Universitas PGRI Semarang. Analisis data post test dilakukan untuk mengetahui apakah kelas kontrol dan kelas eksperimen, memiliki perbedaan antara pembelajaran konvensional dan pembelajaran dengan menggunakan media mobile learning dengan pendekatan matematik realistik.

Untuk menghitung normalitas data awal dilakukan dengan menggunakan uji Liliefors dengan taraf signifikan 5\%. Dari perhitungan diperoleh bahwa $\mathrm{L}_{0}<\mathrm{L}_{\text {tabel }}$ pada kelas control dan kelas eksperimen dengan taraf signifikan 5\% dengan $n_{1}=15$ dan $\mathrm{n}_{2}=12$ sehingga Ho diterima. Hal ini berarti sampel dari kelas eksperimen dan kelas kontrol berasal dari sampel yang berdistribusi normal.

Uji homogenitas digunakan untuk menguji kesamaan dua varians. Dari perhitungan dengan MS. Excel diperoleh $\mathrm{F}_{\text {hitung }}=1,21$, dengan $\alpha=0,05$ dan $\mathrm{dk}$ pembilang $(15-1=14)$, dk penyebut (12 $-1=11)$, sehingga $\left.\mathrm{F}_{(0,05)(14,11}\right)=2,74$. Kriteria pengujian terima Ho jika $\mathrm{F}_{\text {hitung }}<$ $\mathrm{F}_{\text {tabel }}$. Karena $\mathrm{F}_{\text {hitung }}<\mathrm{F}_{\text {tabel }}$ yaitu 1,21 $<$ 2,74 maka Ho diterima, sehingga dapat disimpulkan varians antar kelompok homogen (sama).

Untuk mengetahui pembelajaran mana yang lebih baik maka digunakan pengujian "uji-t" (pihak kanan). Berdasarkan perhitungan dengan MS. Excel diperoleh rata-rata kelas eksperimen yaitu $\overline{X_{2}}=69,83$ dan rata-rata kelas kontrol 
yaitu $\overline{X_{2}}=40,83$ dengan $\mathrm{n}_{1}=15, \mathrm{n}_{2}=12$ dan $\mathrm{s}=12,305$ sehingga diperoleh $\mathrm{t}_{\text {hitung }}$ $=5,98$. Hasil $t_{\text {hitung }}$ dibandingkan dengan $\mathrm{t}_{\text {tabel }}$. Dari daftar distribusi t dengan peluang 0,95 dan $\mathrm{dk}=25$ maka $\mathrm{t}_{0,95(25)}$ adalah 1,71. Dari perhitungan didapat $t_{\text {hitung }}$ sebesar 5,98 dan $t_{\text {tabel }}$ sebesar 1,71. Karena $t_{\text {hitung }}>t_{\text {tabel }}$ yaitu $5,98>1,71$ maka Ho di tolak.

Berdasarkan perhitungan diatas karena Ho ditolak dapat disimpulkan hasil belajar matematika menggunakan media mobile learning dengan pendekatan metamatik realistik lebih baik dibanding dengan model pembelajaran konvensional pada mata kuliah geometri. Hal ini membuktikan ada perbedaan prestasi belajar karena dosen menggunakan dua perlakuan yang berbeda antara kelas kontrol dan kelas eksperimen dengan nilai rata-rata kelas eksperimen yaitu $\overline{X_{1}}=69,33$ dan rata-rata kelas kontrol yaitu $\bar{X}_{2}=40,83$.

Hal ini didukung oleh penelitian Asabere dan Enguah (2012: 61) mengemukakan bahwa " Pembelajaran menggunakan handphone dan ahli sistem, jika diterapkan dapat meningkatkan bakat siswa, untuk penyesuaian dalam melatih setiap siswa khususnya pada basis/ kecepatan belajar mandiri yang memungkinkan siswa untuk mendapatkan pemahaman yang mendalam tentang dasardasar, serta dapat mengikuti topik yang lebih maju dari program CLT 101 atau bidang yang lebih khusus" dan penelitian Kaloo dan Mohan (2012: 17) mengemukakan bahwa "Pembelajaran aljabar menggunakan handphone menunjukkan hasil yaitu murid dari kelas pertama dan kelas kedua menunjukkan peningkatan pencapaian, sedangkan kelas ketiga dimana tidak menggunakan handphone tidak ada perbedaan hasil belajar"

\section{SIMPULAN}

Kesimpulan yang diperoleh dari penelitian pengembangan ini adalah (1) Dihasilkan produk media mobile learning dengan pendekatan matematik realistik yang berbentuk aplikasi apk yang didalamnya membahas mata kuliah geomteri. (2) Pengembangan mobile learning dengan pendekatan matematik realistik layak digunakan oleh mahasiswa. Hal ini dapat dilihat dari penilaian dari ahli media dan ahli materi. Hasil validasi oleh ahli media sebesar 93\%. Hasil validasi oleh ahli materi sebesar 83\%. Setelah dikonversi dengan tabel konversi skala, kedua persentase pada ahli media dan ahli materi berada pada rentang $81 \%$ - 100\%, jadi media mobile learning dengan pendekatan matematik realistik memiliki kategori sangat baik. (3) Perbandingan prestasi belajar antara kelas eksperimen dan kelas kontrol diperoleh, kelas eksperimen yang menggunakan media mobile learning dengan pendekatan matematik realistik lebih baik dibandingkan kelas kontrol yang menggunakan pembelajaran konvensional dengan perhitungan diperoleh rata-rata kelas eksperimen yaitu $\overline{X_{1}}=69,33$ dan rata-rata kelas kontrol yaitu $\bar{X}_{2}=40,83$. Dengan menggunakan uji-t pihak kanan. Hasil uji$\mathrm{t}$ menunjukan bahwa $\mathrm{t}_{\text {hitung }}=5,98$ dan $\mathrm{t}$ tabel $=1,71$ jadi dapat disimpulkan $\mathrm{t}_{\text {hitung }}>$ $\mathrm{t}_{\text {tabel }}$ yaitu 5,98 $>1,71$ nilai t dengan taraf signifikan 5\%. Kesimpulannya adalah $\mathrm{t}_{\text {hitung }}$ $>\mathrm{t}$ tabel maka Ho ditolak.

Berdasarkan hasil penelitian yang diperoleh, maka saran yang sekiranya dapat diberikan peneliti sebagai bahan pertimbangan untuk perbaikan proses pembelajaran adalah sebagai berikut. (1) Media mobile learning dengan Pendekatan Realistik Matematik sebaiknya digunakan dosen dalam kegiatan 
pembelajaran karena terbukti dari hasil penelitian yang diperoleh, hasil belajar peserta didik yang mendapatkan pembelajaran dengan Media mobile learning dengan Pendekatan Realistik Matematik lebih baik dibandingkan hasil belajar mahasiswa yang menggunakan model konvensional. (2) Media mobile learning dengan Pendekatan Realistik Matematik perlu diterapkan oleh dosen dan terus dikembangkan pada mata kuliah yang lain agar dapat mengembangkan berbagai aktivitas dan kreativitas mahasiswa dalam pembelajaran.

\section{DAFTAR PUSTAKA}

Ally, Mohamed. (2009). Mobile Learning Transforming the Delivery of Education and Training. Canada: AU Press

Asabere, N.and Enguah, S. (2012). "Use of Information \& Communication Technology (ICT) in Tertiary Education in Ghana: A Case Study of Electronic Learning (E-learning)”. International Journal of Information and Communication Technology Research. 2(1), pp.62-68.

Borg, W. R dan Gall.M. D. (1983). Educational Research An Introduction. New York: Longman

Gravemeijer, Koeno dkk. (2001), Participating in Classroom Mathematical Practices, Journal of the Learning Sciences, 10 (1), 113-163.

Hans Freudenthal. 2002. Didactical Phenomonology of Mathematical Structures. Kluwer Academic Publisher: New York
Heck. A \& Widjaja, Y. B. 2003. How a Realistic Mathematics Education Approach and MicrocomputerBased Laboratory Worked in Lessons on Graphing at an Indonesian Junior High School. Journal of Science and Mathematics Education in Southeast Asia, 2003, 26 (2): 1-51.

http://p4tkmatematika.org. Mobile Learning. (diakses pada 2 Mei 2015).

Inch, E. S., et al. (2006). Critical Thinking and Communication: The use of reason in argument. 5th Ed. Boston: Pearson Education, Inc.

Kaloo dan Mohan. 2012. MobileMath: An innovative solution to the problem of poor Mathematics performance in the Caribbean. Caribbean Teaching Scholar Vol. 2, No. 1, April 2012, 5-18.

Martinez, Jose Lopez dkk. (2014), Development of a Mobile Service on a WiFi Network for the Evaluation of Mathematical Skills, International Journal of Computer Science Issues, 11 (2), 1-7.

Shao. (2014), MoMath: An Innovative Design of a Mobile based System for Supporting Primary School Mathematics in Tanzania, International Journal of Computer Applications, 95 (15), 22-27.

Soedjadi. 2004. Pendidikan Matematika Realistik. Surabaya : Unesa 